\title{
Multiple authorship and financial support
}

Dear Sir,

The proliferation of authors has been previously discussed [1]. In large part, blame for this must rest with those authorities (state and private) which insist that grants can only be given to those who can prove their active involvement in research through publications. EASD itself must bear some of the blame by their regulation that each submitted abstract for its Annual Meetings must be in the name of a different individual. Because travel grants are generally awarded only to first authors, there is a tendency for work to be sub-divided into sectional reports which may well be individually rejected, whereas the whole might have been accepted. Grants should be given on the basis of involvement in research rather than the often haphazard roulette of first authorship.

Perhaps EASD travel grants should be given only to co-authors, or to those whose abstracts have been rejected, as a way of encouraging renewed efforts. After all, it is mandatory that presenting authors of an accepted abstract shall attend the meeting for which the ab- stract is submitted: this implies an advance commitment by the author (or by his/her department) to support the expenses of attendance. If an abstract is submitted, it is presumably in the belief that its content is sufficiently inspiring to ensure its presentation. Or is it just the sprat (submission) to catch the mackerel (financial support)?

Yours sincerely, James G. L. Jackson

Executive Director

European Association for the Study of Diabetes

\section{Reference}

1. Berger M (1986) Letter to the reader: 1986. Diabetologia 29: $825-826$ 